\title{
Formação do professor do atendimento educacional especializado: a Educação Especial em questão
}

Elisabeth Rossetto*

\section{Resumo}

O presente artigo tem como objetivo discutir a formação e as atribuições do professor do Atendimento Educacional Especializado (AEE) realizado na Sala de Recursos Multifuncional (SRM). O estudo em questão é de caráter documental e bibliográfico. $\mathrm{Na}$ investigação documental, selecionamos normativas legais que se referem especificamente ao $\mathrm{AEE}$, considerando-se que este se constitui no espaço prioritário para o atendimento aos alunos com deficiência inseridos no ensino regular. A parte bibliográfica deu-se sob o enfoque da Teoria Histórico-Cultural, por ser o referencial teórico que tem contribuído significativamente ao se tratar do processo de escolarização da pessoa com deficiência. Nossa investigação levou-nos a perceber que a preparação direcionada ao professor encontra-se imbuída de características que denotam superficialidade teórica, com grande adesáo à modalidade de Educaçáo a Distância (EAD), com ênfase em procedimentos técnicos e na disponibilização do uso de recursos. Entendemos que tal formação não contribui para o processo de apropriaçáo de conhecimentos por parte dos alunos e compromete a socialização dos conteúdos escolares e $o$ ato de ensinar. Nesse sentido, reconhecemos a relevância de investimentos em uma qualificação mais consistente, que instrumentalize teoricamente o professor. Ademais, a partir deste referencial, ressaltamos a importância da açáo docente enquanto mediação para o processo de escolarizaçáo e humanizaçấo dos alunos com deficiência, uma vez que está no conhecimento uma via pela qual o aluno com deficiência compensa suas limitaçôes e é capaz de superar as características causadas pela própria deficiência.

Palavras-chave: Atendimento Educacional Especializado; Formação docente; Educação Especial. 


\section{Teacher training of educational service specialist: a Special Education concerned}

\section{Abstract}

This article aims to discuss the formation and powers of the teacher of the Specialized Educational Support Services conduced at the multifunctional resource room. The study in question is documentary and bibliographic. On desk research we have selected legal normatives that relate specifically to the Specialized Educational Support Services, whereas this constitutes the priority space to the service to students with disabilities placed in regular education. The bibliographic part took place about the focus of the Historic-Cultural Theory, to be the theoretical framework which has contributed significantly to the case of the disabled person's schooling process. Our research led us to realize that the preparation directed to the teacher is imbued with characteristics that denote theoretical superficiality, with large membership to the mode of distance learning, with emphasis in the technical procedures and in the availability of resource use. We understand that such training does not contribute to the process of acquiring knowledge by students and commits the school content and the act of teaching. Accordingly we recognize the relevance of investments in a more consistent classification that theoretically instrumentalizes the teacher. Moreover from this reference, we emphasize the importance of the teaching activities as mediation in the process of education and humanization of impaired students, since knowledge is a way by which the impaired student compensates his limitations and is able to overcome the characteristics caused by the disability itself.

Keywords: Specialized Educational Services; Assignments Teacher; Teacher Training; Special Education.

\section{Introdução}

O presente artigo tem como objetivo discutir a importância da formação docente para o Atendimento Educacional Especializado (AEE) da Sala de Recursos Multifuncional (SRM) e as atribuiçôes direcionadas a esse profissional. Assim, por meio da legislação vigente, procuramos identificar a formação do professor e o trabalho educacional proposto. Em relação aos documentos oficiais, contemplamos aqueles que organizam o AEE nos moldes atuais e direcionam a formação docente, com vistas às possíveis contribuiçóes da ação pedagógica neste espaço para o processo de escolarização de alunos com deficiência.

A Política Nacional de Educação Especial na Perspectiva na Educação Inclusiva, de 7 de janeiro de 2008 (BRASIL, 2008), apresenta orientaçôes para a educação especial brasileira e dá direcionamento às normativas e açôes subsequentes. A partir dessa, vários documentos se encarregaram de organizar e direcionar o AEE na SRM. Esse espaço é colocado como proposição central para apoio aos alunos. Neste sentido, abordamos: a Nota Técnica SEESP/GAB/Nn. 11/2010 que apresenta orientaçôes para a institucionalização da oferta do Atendimento Educacional Especializado 
(BRASIL, 2010b); a Resolução CNE/CEB n. 04, de 02 de outubro de 2009, que institui as diretrizes operacionais para o AEE na Educação básica, na modalidade de educação especial (BRASIL, 2009a); e a Nota Técnica SEESP/GAB n. 09/2010, de 9 de abril de 2010, que apresenta orientaçóes para os centros de AEE (BRASIL, 2010a).

Consideramos que apenas a leitura dos documentos governamentais não nos permite visualizar a sua intencionalidade. Entendemos, entấo, que se torna relevante a análise dos conceitos presentes no discurso divulgado pelas publicaçóes do governo federal. Compartilhamos a opiniáo de que "os sentidos não são dados nos documentos, são produzidos; estão aquém e além das palavras que os compõem” (SHIROMA; CAMPOS; GARCIA, 2005, p. 1). Assim, eles só podem ser entendidos tendo como parâmetro o contexto de sua elaboração e o próprio contexto de produção da vida nesta sociedade.

Nesse sentido, o presente artigo resulta de um estudo documental e bibliográfico. Na investigação documental, priorizamos materiais representativos da educação especial na perspectiva inclusiva, pois tal modalidade investigativa é recurso para conhecer a proposta divulgada pelo Ministério da Educaçáo (MEC) para o trabalho docente na SRM. A pesquisa bibliográfica, por sua vez, subsidia a análise dos documentos por meio da compreensáo do contexto social que nos determina e do aprofundamento sobre a especificidade do desenvolvimento da pessoa com deficiência. Temos como base a Teoria Histórico-Cultural de Vigotski, principalmente a obra do Tomo V desse autor, de forma articulada com as questóes contemporâneas, na pretensão de estabelecer discussóes acerca dos possíveis encaminhamentos metodológicos àqueles alunos que, por uma ou outra razão, aprendem de maneira diferente.

\section{Atribuições e formação do professor do AEE}

As normativas mencionadas indicam a realização do AEE na SRM e o destacam como subsidiador para o processo inclusivo dos alunos da educaçáo especial, uma vez que não são propostas, em nível de legislaçáo nacional, outras formas de apoio. $\mathrm{O}$ trabalho pedagógico relacionado ao ensino e a especificidade da ação educacional, nesse contexto, não se apresentam claramente. $\mathrm{O}$ mesmo se pode considerar acerca da formação necessária ao professor do AEE. Notamos, entretanto, a ênfase na apresentação do professor do AEE que trabalha na SRM como articulador da organização necessária para a escolarização de seus alunos.

Temos claro, nos referidos documentos, que as atividades do AEE na SRM se diferenciam das realizadas em salas de aula do ensino comum, visto que sáo de complementaçáo ou suplementaçáo e que a proposta desse serviço deve se articular com a sala regular. Procuramos, no entanto, a caracterização do trabalho pedagógico do professor no $\mathrm{AEE}$, compreendendo os fundamentos teóricos que dáo suporte às açóes do professor. Esta investigação nos remete a formação docente. Conforme se pode perceber, na Resolução n. 4, de 2009, uma intensa carga de responsabilidade é direcionada ao profissional do AEE, que tem como atribuiçôes: 
I - identificar, elaborar, produzir e organizar serviços, recursos pedagógicos, de acessibilidade e estratégias considerando as necessidades específicas dos alunos público-alvo da Educaçáo Especial;

II - elaborar e executar plano de Atendimento Educacional Especializado, avaliando a funcionalidade e a aplicabilidade dos recursos pedagógicos e de acessibilidade;

VI - orientar professores e famílias sobre os recursos pedagógicos e de acessibilidade utilizados pelo aluno;

VII - ensinar e usar a tecnologia assistiva de forma a ampliar habilidades funcionais dos alunos, promovendo autonomia e participação;

VIII - estabelecer articulação com os professores da sala de aula comum, visando à disponibilização dos serviços, dos recursos pedagógicos e de acessibilidade e das estratégias que promovem a participaçáo dos alunos nas atividades escolares. (BRASIL, 2009a, p. 3).

Há ainda outros documentos que apresentam as atribuiçóes do professor, como as Notas Técnicas SEESP/GAB/N.09 (BRASIL, 2010a) e SEESP/GAB/N.11 (BRASIL, 2010b). É previsto o trabalho direto com o aluno em período de contraturno, o trabalho colaborativo para subsidiar as açóes e a formação do professor da sala regular, além da elaboração de materiais específicos para uso dos alunos nas salas de aula, a orientação à família e a articulação com setores e profissionais externos à escola. Percebe-se que, nos documentos citados, as atribuiçóes compreendem várias atividades organizativas e articuladoras dentro do espaço escolar e, possivelmente, fora dele. Reiteramos a preocupação em relação às atividades do AEE, no que se refere à redução da atividade de ensino, bem como à omissão completa do trabalho com os conteúdos escolares.

A supressão do trabalho com os conteúdos escolares, ao mencionar as atribuiçóes do professor, não se trata de uma omissão sem significado por parte dos documentos em questấo. Trata-se de um fato revelador da intencionalidade de adotar uma concepção de educaçáo, segundo a qual tanto o ensino quanto o elemento circunstancial dessa ação, o conteúdo escolar, são relegados. Temos, assim, um indicativo que nos permite inferir que as proposiçóes para o trabalho docente na SRM carregam em si uma descaracterização da atividade do professor, pois o ensino é secundarizado nas normativas que organizam o setor.

Entre as responsabilidades do professor, constata-se dois espaços de atuação, com a existência da SRM tipo 1 e da SRM tipo 2. Cada espaço dispóe de materiais diferenciados, sendo que a segunda se destina, também, ao trabalho com alunos da área visual e a primeira o trabalho com alunos das demais áreas que compóe o público alvo da educação especial. 
Nesse sentido, por meio da SRM, o mesmo professor pode trabalhar com várias áreas. É questionável a viabilidade da execução de tarefas tão diversas por um mesmo profissional. Há uma grande distância entre o trabalho especializado a ser desenvolvido para a pessoa com deficiência física e para a pessoa surda, por exemplo. Cada área tem um conhecimento específico. Cabe a organizaçáo dos sistemas de ensino e a realização da formação constante para o professor. Não há, no entanto, pela via das normatizaçóes, a previsão de uma formação específica para os profissionais de um espaço ou de outro (SRM tipo 1 ou tipo 2). Fica implícita, nos documentos, a ideia de que todos podem fazer tudo por meio da força de vontade e do desprendimento individual.

Concordamos com o posicionamento de $\operatorname{Vaz}(2013$, p. 183) que, ao analisar as atribuiçôes do professor, compreende que a multifuncionalidade é expressa também nas açōes desse profissional e sugere a conceituação de "professor multifuncional". Além da desconsideraçáo da atividade de ensino dos conhecimentos formais, o professor recebe uma sobrecarga de tarefas e tem a incumbência de, em nome da conscientizaçáo do grupo escolar, persuadir os demais professores para a efetivação da proposta inclusiva.

Com base nas diversas açôes que o professor do AEE deve desempenhar dentro de cada área que compóe o alunado da SRM, desde o trabalho direto com o aluno até a articulação com a família e os setores externos à escola que possam apoiar o desenvolvimento do aluno, supomos que sua formação precisa instrumentalizá-lo para que dê conta de várias atividades que exigem conhecimento específico. Assim, buscamos, nos documentos, as definiçôes da formação necessária. A Política Nacional de Educação Especial na Perspectiva da Educação Inclusiva (BRASIL, 2008) informa:

Para atuar na educação especial, o professor deve ter como base de sua formaçáo, inicial e continuada, conhecimentos gerais para o exercício da docência e conhecimentos específicos da área. Essa formação possibilita a atuação no atendimento educacional especializado e deve aprofundar o caráter interativo e interdisciplinar da atuação nas salas comuns do ensino regular, nas salas de recursos, nos centros de atendimento educacional especializado, nos núcleos de acessibilidade das instituiçóes de educação superior, nas classes hospitalares e nos ambientes domiciliares, para a oferta dos serviços e recursos da educação especial. (BRASIL, 2008, p. 17-18).

A Resolução n. 4 de 2009 estabelece que "para atuação no AEE, o professor deve ter formaçáo inicial que o habilite para o exercício da docência e formação específica para a educação especial" (BRASIL, 2009a, p. 3). Não há, nos documentos, a indicação de uma formação inicial distinta. Subentende-se que a formação específica dá-se em serviço, mas não há uma especificação precisa acerca de qual o curso que contempla o conhecimento necessário ao professor com base no trabalho na SRM.

Assim, a organização da formação para o trabalho pedagógico para a SRM dá-se no curso da implantação do serviço, não há uma capacitação prévia. São os professores que já atuavam na educação especial que adentram nessa atividade com novas 
atribuições, cuja preparação efetiva-se por meio da formação continuada. Abre-se, também, a possibilidade para que o professor que tem formação inicial para docência em qualquer área e um curso de formação continuada em AEE, trabalhe na SRM.

Vaz (2013), após estudo acerca da formação docente, constata que o professor do AEE, tal como descrito na documentação, não coincide com o professor de educação especial, o que é expresso tanto em sua atuação, que requer novas práticas quanto na sua formação. Conforme expresso no documento Diretrizes Nacionais para a Educação Especial na Educação Básica (BRASIL, 2001), o professor tinha como exigência a formação em nível de graduação ou pós-graduação em educação especial: formação inicial em cursos de licenciatura e especialização (lato sensu) na área; ou, formação inicial de graduação em educação especial ou graduação com habilitação em educação especial.

Atualmente, o professor para o AEE não tem previsão de formação inicial específica e sua formação consiste nos cursos de formação continuada e especialização em AEE, ou seja, há uma restriçáo da preparaçáo desse profissional, com vista à exclusividade da formaçáo em serviço. Mesmo aquele profissional que já trabalhava na educação especial com a formação exigida, agora, para trabalhar no AEE, precisa aderir à formação em AEE. Portanto, há ênfase na formação continuada para a disseminação dos novos princípios da educação especial e para a efetivação da educação inclusiva.

Nos documentos representativos da educação especial que dispóem sobre a organização do AEE, encontram-se poucas mençôes acerca da formação que atualizaria esse profissional aos princípios inclusivos. Porém, localizamos tal resposta nas ações apresentadas pelo MEC que demonstraram a centralidade da formação continuada na modalidade da Educação a Distância (EAD).

A formação na modalidade da EAD tem sido uma via muito utilizada para a formação continuada de professores, entre os quais também é contemplado o profissional que atua no AEE. Apoiados na Portaria Normativa n. 12, de 24 de abril de 2007, que dispóe sobre a criação do "Programa de Formação Continuada de Professores na Educação Especial" (BRASIL, 2007b), além de cursos de formação continuada, foram aprovados pelo MEC, por meio de instituiçóes públicas de educaçáo superior, cursos de especialização - lato sensu - que tiveram grande abrangência em todo o país na modalidade da EAD, no âmbito do Programa Universidade Aberta do Brasil (UAB). ${ }^{1}$

No ano de 2007, por meio do Edital n. 2, de 26 de abril, a União Federal, representada pelo MEC, por intermédio da Secretaria de Educação Especial, realizou, em chamada pública, a convocação das instituições públicas de ensino superior para participar da seleçáo de propostas de cursos de formaçáo continuada para o AEE para professores em nível de extensão, na modalidade a distância, no âmbito do Programa UAB. Nesse caso, o curso foi proposto em nível de extensão ou pós-graduação, na modalidade a distância, com carga horária de 120 horas (BRASIL, 2007c). 
Em 2009, por meio do Edital n. 1, de 2 de março, o MEC realizou nova chamada para cadastramento e seleção de cursos de instituiçóes públicas de educação superior para a rede de formação continuada de professores na educação especial no âmbito UAB. A proposição consistiu em ofertar um curso de extensão ou aperfeiçoamento, de 180 horas, e especialização para a formaçáo continuada de professores que atuam no AEE, de 360 horas, bem como extensão ou aperfeiçoamento para a formação continuada de professores que trabalham nas classes comuns de 180 horas (BRASIL, 2009b).

Assim, de acordo com informaçóes obtidas na página eletrônica do MEC, somente no período de 2007 a 2010, foram ofertados 55 cursos de formaçáo para

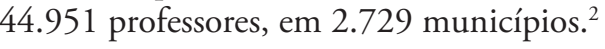

Um olhar mais crítico revela que, embora os cursos de EAD, on-line, abarquem a formação de grande quantidade de profissionais e pareçam uma estratégia convidativa e confortável, escondem uma formação docente limitada e aligeirada que, supostamente, é justificada pela urgência de formar o profissional para uma tarefa imediata. Dessa forma, o professor enfrenta o dilema de conduzir o processo de ensino/aprendizagem rumo à humanização dos alunos, quando sua própria formação é comprometida. O professor do AEE tem atribuiçóes diversas em campos de conhecimento específicos, mas, para o desempenho de sua funçáo, contraditoriamente, coloca-se uma formação cuja consistência é questionável.

Esse diálogo precisa ser ampliado com pesquisas que versem sobre a formação continuada de professores na modalidade a distância. Reconhecemos a importância do desenvolvimento de discussóes e processos investigativos que contemplem a fragilidade existente nesta modalidade de ensino e que possam conhecer os efeitos dessas formaçóes nas configuraçóes das práticas pedagógicas na medida em que temos a intensificação de açôes formativas nestas condiçôes.

Malanchen (2007, p. 213), em estudo acerca dos cursos de EAD, esclarece que esta é, na verdade, mais uma das formas para "despolitizar e controlar o professor". Afirma que a influência dessa configuração de formaçáo, além de responder a intenção de redução dos custos, colabora para a gradativa "desintelectualização" do professor. A autora explica que

A desintelectualização ocorre também pelos princípios que regem os cursos de EAD, em sua maioria, que são os de aproveitar a prática do professor para realizar uma reflexão colada na empiria, afastando, assim, a formação deste de uma teoria científica, logo, mais elaborada. (MALANCHEN, 2007, p. 214).

A limitação pragmática dos estudos da educação especial, promovida pelos cursos de EAD, pode ocasionar um recuo da área (como campo de conhecimento) e pouco desenvolvimento em relaçáo a aspectos que precisam ser superados na educação das pessoas com deficiência. A preparação do professor dá-se de modo emergencial e defende um conhecimento pragmático e imediato com graves limitações no que 
diz respeito à compreensão da realidade e à fundamentação teórica/epistemológica. A formação do professor ao ser precarizada pela contenção de custos financeiros, atendida pelo modelo de EAD, harmoniza-se com a negação do conhecimento para os alunos da escola pública. De acordo com Martins:

Ao longo do século XX, os ideais humanizadores da educação escolar; ainda que nos limites da humanização burguesa propalada nos primórdios da educação escolar; esvaem-se pelos meandros de sucessivas formas e reformas pelas quais se ordenou a sociedade do capital. Em estreita sintonia com essa ordem se estruturam e se firmam, de modo orgânico, os ideários pedagógicos que hegemonicamente nortearam, e continuam norteando, tanto a prática quanto (e para tanto!), a formação de professores. (MARTINS, 2010, p.16, grifos da autora).

Compreendemos, assim, que a formação superficial dos professores se relaciona com a banalização do conhecimento para a classe trabalhadora. A preparação docente está vinculada a formação que se pretende para o aluno e ambas são determinadas pelo projeto de sociedade em vigor, que expropria a maioria da população tanto econômica quanto culturalmente.

Nota-se que, assim como a educação, o professor está inserido num contexto histórico-social determinado pelas contradiçóes da sociedade capitalista. Nesse contexto, "um dos maiores legados do século XX para a formaçáo docente foi o acirramento da sobrevivência deste profissional às demandas hegemônicas do capital" (MARTINS, 2010, p. 8). A expropriação do professor em relação ao conhecimento científico é um dos problemas para a educação, situação que resulta no esvaziamento da atividade docente. $\mathrm{O}$ professor, como toda a classe trabalhadora, está exposto às condiçóes degradantes que inviabilizam as possibilidades efetivas de humanização.

O AEE e a Educação Especial

Paralelamente à redução da atividade docente e à formação do professor direcionada para o AEE, a educaçáo especial, como área de pesquisa e campo de conhecimentos, é desvalorizada, conforme se constata no documento "Atendimento Educacional Especializado: aspectos legais e orientaçóes pedagógicas” (BRASIL, 2007a), pois, em várias ocasióes ao longo desse material, há a defesa de que o AEE é equivalente à educação especial, como vemos no argumento abaixo:

[...] louvamos os termos da Constituição Brasileira e das convençôes internacionais que nos permitem concluir que o Atendimento Educacional Especializado, destinado a alunos com deficiência, também chamado de Educação Especial, é uma forma válida de tratamento diferenciado. (BRASIL, 2007a, p. 20, grifos nossos).

Destaca-se, portanto, um movimento de mudanças que não apenas questiona a educação especial como aponta para a substituição dessa nomenclatura e, possivelmente, dessa área. O AEE assume tamanha relevância nos documentos divulgados 
que há indicativos de que ele substitua ou seja equivalente à educação especial. A proposição do uso da nomenclatura "Atendimento Educacional Especializado" se dá, entre outros, devido à intenção de defender um novo conceito para a educação especial, pois "ela sempre foi entendida como capaz de substituir o ensino regular" (BRASIL, 2007a, p. 28). Em relação a isso, Beyer (2010) alerta:

[...] estamos certamente diante de um movimento internacional de revisão de pressupostos fundamentais da educação especial. As posições neste sentido parecem se alinhar por duas tendências: a) uma abordagem de aproximação de áreas, em que se defende a ideia de relevância das funçóes da educaçáo especial como elemento de suporte às propostas da educaçáo inclusiva; e b) uma abordagem mais radical de crítica à educação especial, considerando-se que esta, pela sua tradição clínico-terapêutica, tenderia mais a prejudicar do que ajudar as propostas de educação inclusiva. (BEYER, 2010, p. 6).

Temos, entre as distintas opinióes, aquelas que valorizam os conhecimentos já existentes, enquanto há outras que os questionam. O entendimento presente nas divulgaçóes do MEC parece estar mais voltado ao segundo posicionamento, pois há um incentivo à substituição da educaçáo especial pelo AEE, como defesa de que este contemplaria a proposta inclusiva.

Configuram-se, portanto, dois movimentos que convergem para a superficialidade da formação direcionada ao professor: a substituição da educação especial pelo $\mathrm{AEE}$ associada à padronização dos cursos de $\mathrm{EAD}$ como forma de capacitação desse novo profissional. O professor continuou alheio aos conhecimentos gerais que envolvem a educação e distanciou-se dos conhecimentos específicos da área.

Há uma especificidade formada a partir de conhecimentos acumulados que subsidiam o trabalho na educação especial. Por outro lado, caso esta área se coloque alheia às discussões teóricas que envolvem a educaçáo para a classe trabalhadora, fica isolada e perde seu significado. Vigotski (1983) alertava que a teoria e a prática da educação da criança com atraso profundo, por muito tempo, foram excluídas das vias principais pelas quais transcorria a psicologia e a pedagogia; assim condenadas a um desenvolvimento extremamente lento.

Uma interpretação da ideia defendida pelo autor, que a relacione ao atual contexto da educaçáo especial, nos permite compreender que, ao mesmo tempo em que não podemos reter os estudos da área num campo isolado como se fosse independente dos demais, eliminar os conhecimentos peculiares da educação especial também não é coerente. Para que o professor possa desenvolver uma ação pedagógica que contemple as necessidades dos alunos por meio da SRM é necessária uma formação que contemple a especificidade desse trabalho.

Por meio da educação especial, talvez seja possível buscar vias para superar o barateamento a que foi destinada a formação docente para o AEE. Algumas questóes específicas da educação especial, como os conhecimentos que dizem respeito à área da 
surdez e à área visual, por exemplo, são indispensáveis ao professor. Mas há também conhecimentos necessários a todos os profissionais, como o estudo das bases teóricas que explicam o desenvolvimento humano e a pesquisa de referenciais que contemplam esse desenvolvimento na pessoa com deficiência.

Para que a educação especial não se enclausure nas próprias discussôes nem fique restrita a um conjunto de técnicas, faz-se necessária a participação dos profissionais nas discussóes que abordam os determinantes sócio-históricos da prática educativa desenvolvida no ensino comum. Para que o trabalho pedagógico na SRM contemple as necessidades dos alunos e os eleve culturalmente, o professor precisa de antemáo apropriar-se do desenvolvimento cultural que lhe permitirá orientar o processo educativo.

\section{$\bigcirc$ AEE como um conjunto de serviços}

Com o intuito de encaminhar a conclusão do referido trabalho, cabe retomar que o estudo, acerca do processo educacional das pessoas com deficiência, nos revela um quadro histórico de exclusão, com o predomínio de práticas segregativas como única possibilidade educativa. No entanto, as normativas mais recentes, bem como a luta das pessoas com deficiência, indicam a oportunidade de acesso à escolarizaçáo, dentre outros direitos sociais. Constatamos, assim, que a crescente inclusão de alunos com deficiência no ensino regular é um processo recente, que tem se apresentado como assunto frequente nas discussóes educacionais, tanto que uma das preocupaçôes presentes no diálogo entre os educadores é o atendimento às necessidades dos seus alunos, pois exigem recursos diferenciados e uma organizaçáo distinta do ensino. Nesse contexto, a existência de formas de apoio e a disposição de determinadas condiçôes nas escolas são colocadas em pauta.

O AEE é uma temática em evidência, se apresenta como um apoio significativo para as escolas regulares, tendo em vista o crescente número de alunos com deficiência que ingressam no ensino comum e a ênfase dada a este serviço, principalmente após a publicação do documento Política Nacional de Educação Especial na Perspectiva da Educação Inclusiva (BRASIL, 2008). Segundo este, o AEE tem a funçáo de "identificar, elaborar, e organizar recursos pedagógicos e de acessibilidade, que eliminem as barreiras para a plena participação dos alunos, considerando suas necessidades específicas" (BRASIL, 2008, p. 8).

Esse atendimento constitui-se com uma rede de serviços destinados ao público da educação especial, isto é, aos "alunos com deficiência, transtornos globais de desenvolvimento e altas habilidades/superdotação" (BRASIL, 2008, p. 7). Perpassa todos os níveis e modalidades de ensino em caráter complementar e/ou suplementar. Desta forma, a legislação traz uma nova abordagem para a educaçáo especial adequada à perspectiva inclusiva, pois propóe significativas modificaçôes para o atendimento ao alunado e destaca a inclusão dos alunos com deficiência na escola regular.

Entre as atividades do AEE, organizadas a partir de 2008, podemos ainda citar que este: apoia o desenvolvimento dos alunos; disponibiliza o ensino de linguagens e de códigos específicos de comunicação e sinalização; oferece Tecnologia Assistiva 
(TA); faz adequaçóes e produz materiais didáticos e pedagógicos, tendo em vista as necessidades exclusivas de cada aluno; e oportuniza o enriquecimento curricular para alunos com altas habilidades/superdotação. Diante dessa organização, estabelecida pelos documentos oficiais, o AEE é compreendido como um conjunto de serviços, e a atividade docente voltada ao ensino dos conteúdos não é mencionada. Assim, notamos uma ênfase às questóes técnicas, referentes ao uso de recursos, o que indica a secundarizaçáo dos aspectos pedagógicos, relacionados ao ato de ensinar. Em consequência, consideramos a possibilidade de que, por meio das normativas, a aprendizagem também seja prescindida. De acordo com Michels:

[...] a centralidade das açóes dos professores do atendimento educacional especializado (AEE) permanece nas técnicas e nos recursos especializados [...]. Mesmo aquelas açôes que dizem respeito à articulação com a classe comum não estão atreladas à discussão pedagógica, e sim a utilização de recursos específicos. (MICHELS, 2011, p. 226).

Compreende-se, assim, que, a partir de 2008, o AEE adquiriu definições mais precisas que permitem a implementação em âmbito nacional. Â medida que é reforçado o indicativo de que a escolarizaçáa das pessoas com deficiência deve se dar no ensino comum da escola regular, ascende a necessidade de apoio de um atendimento diferenciado que dê suporte a professores e alunos, uma vez que não basta a inserção desse alunado na sala comum, fazem-se necessárias condiçóes e suportes adequados. No entanto, na projeção da ação educacional do AEE, há ênfase nas questóes relativas a procedimentos técnicos, como disponibilização de recursos. Assim, constatamos o afastamento dos propósitos pedagógicos, o enfraquecimento da atividade docente e, consequentemente, a redução das possibilidades de aprendizagem.

O termo "Atendimento Educacional Especializado" começou a ser citado com a possibilidade de um novo sentido na educação das pessoas com deficiência, uma forma distinta de compreender as suas necessidades, tendo em vista a complementação exigida. Cabe mencionar que, em períodos anteriores, as necessidades que esses alunos tinham de um tratamento diferenciado foi argumento e motivo para que eles fossem encaminhados para espaços segregados como única forma de educação. Agora, o encaminhamento por meio do AEE pode se dar na escola regular; no entanto, parece-nos que os objetivos que tal atendimento assume náo se vinculam ao ensino, menos ainda à abordagem dos conteúdos escolares.

A definição da escolarização dos estudantes da educação especial, no que diz respeito à proposta do AEE nas SRM, está mais associada à socializaçáo, no sentido da presença física, frequência e convivência, do que ao processo de apropriação do conhecimento escolar. Diante de tal propósito, a função do professor do AEE - isenta do compromisso com o ensino de conteúdos - e a disponibilidade de um conjunto de recursos técnicos, de acessibilidade e pedagógicos, tornam-se adequadas. Vaz (2013) afirma que "a formação aligeirada e sem discussão teórica faz parte do projeto educacional que está em vigor” (p. 141). 
Constatamos, então, que o AEE assume centralidade nas proposições de apoio à educação ao ser promovido no discurso de sucesso individual pela inclusão e ao ser colocado como a garantia de viabilidade desse processo. Além disso, ele não tem ênfase no ensino e na aprendizagem, mas no fornecimento de aparato técnico, bem como na formaçáo da capacidade de uso desses recursos. Portanto, esse atendimento está no bojo das açôes que atualizam a educação de acordo com as expectativas do homem com capacidade técnica e habilidades imediatas para o processo produtivo no mundo globalizado.

\section{Conclusão}

Com base no estudo realizado, podemos dizer que a formação dos professores, dentre estes aqueles que se dedicam ao AEE, é intensamente influenciada por investidas que negam o saber formal para a classe trabalhadora. A formação a distância, associada à desvalorizaçáo da educaçáo especial enquanto campo de conhecimento, resulta numa preparaçáo docente emergencial que defende um conhecimento subentendido e imediato, com limitaçóes no que diz respeito à compreensão da realidade e à fundamentação teórica. Bem como, as açóes implementadas pelo MEC nos permitem dizer que este enfraquecimento da ação pedagógica prevista para a SRM é compatível como a formação que é direcionada ao professor.

Consideramos, portanto, que há ênfase nas questóes técnicas, tanto no apoio prestado pelo AEE como nas atribuiçóes incumbidas ao docente, em detrimento do trabalho com os conhecimentos formais e das atividades de ensino. Constatamos, assim, que há uma redução da tarefa de ensinar do professor e a omissão dos conteúdos a serem ensinados, o que revela a formação de um sujeito com capacidades técnicas e competências de aplicabilidade imediata, condizente com as necessidades atuais do processo produtivo.

Percebemos, por meio da legislação vigente, que há uma centralidade no trabalho da SRM e novas exigências ao professor de educaçáo especial que agora trabalha no AEE. Entendemos, entáo, que a formaçáo do professor e a constituiçáo de uma especificidade para esse serviço são fatores a serem colocados em discussão. Um avanço para a compreensão do trabalho educativo a ser desenvolvido depende do desenvolvimento de pesquisas que contemplem e subsidiem esta área. A formação do professor que trabalha no AEE precisa instrumentalizá-lo para que dê conta de várias atividades que exigem conhecimento específico. Sáo diversas as açóes que deve desempenhar dentro da cada área que compóe o alunado da SRM. Segundo Baptista (2011) ainda "temos um longo caminho a ser percorrido" (p. 66) e

[...] é necessário reconhecer que, além das diretrizes gerais para a organização das salas de recursos, é fundamental garantir espaço de criação de delineamentos para esse serviço em função de características específicas de cada contexto. (BAPTISTA, 2011, p. 71).

Portanto, para os benefícios que o AEE e a SRM possam significar enquanto apoio para o processo de escolarização dos alunos com deficiência, ressaltamos a ur- 
gência da organização de uma formação sólida, pautada em pressupostos epistemológicos condizentes com o que se espera dessa área de estudo; que considere a realidade de cada contexto e ao mesmo tempo, proporcione unidade aos fins dessa atividade docente, assegurando clareza ao professor sobre o trabalho que deve desempenhar, bem como, conhecimento para que o faça. De acordo com Saviani:

[...] será necessário instituir um espaço específico para cuidar da formação de professores para essa modalidade de ensino. Do contrário essa área continuará desguarnecida e de nada adiantarão as reiteradas proclamaçôes referentes às virtudes da educaçáo inclusiva que povoam os documentos oficiais e boa parte da literatura educacional nos dias de hoje. (SAVIANI, 2009, p. 153).

\section{Referências}

BAPTISTA, C. R. Ação pedagógica e educação especial: a sala de recursos como prioridade na oferta de serviços especializados. Revista Brasileira de Educaçáo Especial, Marília, v. 17, p. 59-76, mai./ago. 2011.

BEYER, H. O. Inclusão e Avaliaçáo na escola. 3. ed. Porto Alegre: Mediação, 2010.

BRASIL. Diretrizes Nacionais para a Educação Especial na Educação Básica. Resolução CNE/CEB n. 2 de 11 de setembro. Institui Diretrizes e Normas para a Educaçáo Especial na Educaçáo Básica Ministério da Educaçáo. Secretaria de Educação Especial. Brasília, MEC/SEESP, 2001.

Atendimento educacional especializado - aspectos legais e orientaçóes pedagógicas. Brasília: MEC/ SEESP, 2007a.

. Portaria normativa n. 12 de 24 de abril de 2007. Dispóe sobre a criaçáo do "Programa de Formaçáo Continuada de Professores na Educaçáo Especial”. Ministério da Educação, $2007 \mathrm{~b}$.

Edital n. 02, de 26 de abril de 2007. Programa de Formaçáo Continuada de Professores na Educaçáo Especial. Brasília: SEESP/MEC, 2007c. ESP, 2008

Política Nacional de Educaçâo Especial na Perspectiva da Educação Inclusiva. Brasília: MEC/SE-

Resolução n. 04, de 02 de outubro de 2009. Institui as Diretrizes Operacionais para o Atendimento Educacional Especializado na Educaçáo Básica - Modalidade Educação Especial. Ministério da Educação, Conselho Nacional de Educação, 2009a.

Edital N. 1, de 2 de março de 2009. Chamada Pública para cadastramento e seleçáo de cursos de instituiçóes públicas de educaçấo superior para a rede de formaçáo continuada de professores na Educaçáo Especial no Âmbito do Sistema Universidade Aberta do Brasil - UAB. Diário Oficial, seçâo 3, 2009b.

. Nota Técnica - SEESP/GAB/N. 9/2010. Orientaçôes para a Organizaçáo de Centros de Atendimento Educacional Especializado. SEESP/MEC, 2010a.

Nota Técnica - SEESP/GAB/N. 11/2010. Orientaçóes para a institucionalizaçáo da oferta do Atendimento Educacional Especializado - AEE Salas de Recursos Multifuncionais, implantadas nas escolas regulares. SEESP/MEC, $2010 \mathrm{~b}$.

Presidência da República. Decreto no 7.611, de 17 de novembro de 2011. Dispóe sobre a educaçáo especial, o atendimento educacional especializado e dá outras providências. Brasília, 2011.

MARTINS, L. M. O legado do século XX para a formação de professores. In: MARTINS, L. M.; DUARTE, Newton (orgs). Formaçáo de professores: limites contemporâneos e alternativas necessárias. p. 13-32. São Paulo: Cultura Acadêmica, 2010.

MALANCHEN, J. Políticas de Educação a Distância: Democratização ou Canto da Sereia? Revista HISTEDBR On-line, Campinas, n. 26, p. 209-216, jun. 2007.

MICHELS, M. H. O que há de novo na formação de professores para a Educação Especial? Revista Educaçáo Especial, Santa Maria, v. 24, n. 40, p. 219-232, maio/ago. 2011. 
SAVIANI, D. Formação de professores: aspectos históricos e teóricos do problema no contexto brasileiro. Revista Brasileira de Educaçáo, v. 14, n. 40, jan./abr. 2009.

SHIROMA, E. O.; CAMPOS, R. F.; GARCIA, R. M. C. Decifrar textos para compreender a política: subsídios teórico-metodológicos para análise de documentos. In: Perspectiva, Florianópolis, v. 23, n. 02. Jul./dez. 2005, p. 427-446.

VAZ, K. O Professor de Educaçáo Especial nas Políticas de Perspectiva Inclusiva no Brasil: concepçóes em disputa. Dissertação de Mestrado. UFSC, 2013.

VIGOTSKI, L. S. Obras completas. Tomo V. Fundamentos de Defectología. Cuba: Editorial Pueblo Educación, 1983.

\section{Notas}

${ }^{1}$ A UAB é um programa instituído pelo Decreto no 5.800, de 2006. Tal programa caracteriza-se como um sistema integrado por universidades públicas que oferece cursos de nível superior por meio do uso da metodologia da educação a distância. O público em geral é atendido, mas os professores que atuam na educaçáo básica têm prioridade de formação, seguidos dos dirigentes, gestores e trabalhadores em educaçáo básica dos estados, municípios e do Distrito Federal (informaçōes obtidas no seguinte endereço eletrônico: <http://gestao2010.mec.gov.br/o_que_foi_feito/list_1. php>, acessado em 13 de novembro de 2013).

${ }^{2}$ Dados extraídos do site do MEC: http://gestao2010.mec.gov.br/o_que_foi_feito/program_67.php., acessado em 11 de setembro de 2013.

\section{Correspondência}

Elisabeth Rossetto - Universidade Estadual do Oeste do Parana (UNIOESTE), Centro de Educacáo, Comunicacáo e Artes - CECA. Rua Universitária, 2069. Faculdade, CEP: 85814-110 - Cascavel, Paraná - Brasil.

E-mail: erossetto2013@gmail.com

Recebido em 02 de abril de 2014

Aprovado em 07 de julho de 2014 